\title{
Comparative Gene Analysis of Common Wheat and its Ancestral Species, I. Necrosis ${ }^{11}$
}

\author{
Koichiro Tsunewaki and Hitoshi Kinara \\ National Institute of Genetics, Misima
}

Received October, 5, 1962

There are several approaches to the study of the origin of species. Genome analysis has been successfully applied to some polyploid species such as wheat, tobacco and cotton. Chromosome analysis by means of karyotype studies, translocations or inversions has been a powerful tool for some other organisms such as Drosophila, maize and Oenothera, whose chromosome structures can be cytologically studied in detail. Comparative gene analysis of a given species and its relatives, which is the main subject of this paper, seems to provide an additional approach (cf. Nachtsheim 1959), regardless of polyploidy or easy of cytological handling.

The origin of common wheat has been nearly solved on the genome basis owing to the findings of Kihara (1924, 1944), McFadden and Sears (1944), Sarkar and Stebbins (1956) and Riley, Unrau and Chapman (1958). However, definite information is still lacking on the phylogenetic relationships among various wheat species and their relatives. In order to throw a light on those relations, the present authors have started a comparative gene analysis of common wheat and its relatives. In the present paper, the results are reported from the investigations of necrosis genes.

Since two independent reports by McMillan and Kostyuchenko in 1936 many papers have been published on complementary necrosis in common wheat. Reviewing those results as far as known to him, Hermsen (1959) proposed a "three-gene hypothesis", i.e., three dominant complementary genes, which were later designated as $N e_{1}, N e_{2}$ and $N e_{3}$ by Tsunewaki and Kihara (1961) and Hermsen (1961), are necessary for the expression of all types of necrosis. Tsunewaki (1960) and Tsunewaki and Kihara (1961) located $N e_{1}$ on chromosome 5B (V), Ne on 2A (XIII) and $\mathrm{Ne}_{3}$ on 3D (XVI). Hermsen (1962) described multiple alleles, $N e_{1}{ }^{s}, N e_{1}{ }^{m}, N e_{1}{ }^{w}$ and $n e_{1}$ in the $N e_{1}$ locus, and $N e_{2}{ }^{s}, N e_{2}{ }^{m s}, N e_{2}{ }^{w m}, N e_{2}{ }^{w}$ and $n e_{2}$ in the $N e_{2}$ locus. Further, Tsunewaki and Kihara (1961) suspected the presence of a gene on chromosome 3B (III) that modifies the intensity of necrosis.

Nishikawa (1953, 1962), Sachs (1954) and Roy (1955) also observed similar complementary necrosis in some intergeneric hybrids between Triticum and Aegilops.

1) Contribution from the National Institute of Genetics, Misima, Japan, No. 447. The work has been supported in part by Grant RF 62073 from the Rockefeller Foundation. 
This indicated the presence of some common necrosis genes in both these genera.

Based on their results, Tsunewaki and Kihara (19ô1) designated the following genotypes for three common wheat varieties;

T. aestivum Kharkov: $n e_{1} n e_{1} \mathrm{Ne}_{2} \mathrm{Ne}_{2} \mathrm{Ne}_{3} \mathrm{Ne}_{3}$

T. aestivum Prelude: $\mathrm{Ne}_{1} \mathrm{Ne}_{1} n e_{2} n e_{2} \mathrm{Ne}_{3} \mathrm{Ne}_{3}$

T. macha subletshchumicum: $\mathrm{Ne}_{1} \mathrm{Ne}_{1} \mathrm{Ne}_{2} \mathrm{Ne}_{2} n e_{3} n e_{3}$

Thus any variety producing with one of the above three varieties a necrotic $\mathrm{F}_{1}$ must have at least a dominant allele, for which they are recessive, i.e. $N e_{1}$, $\mathrm{Ne}_{2}$ or $\mathrm{Ne}_{3}$, respectively. Using these varieties as the testers, the distribution of the complementary necrosis genes in common wheat and its direct ancestors, Emmer wheat and Aegilops squarrosa, has been investigated.

Hermsen's three-gene hypothesis is based on a thorough survey of literature and is supported by the later results of monosomic analysis showing that the three genes are located in different chromosomes. However, no critical test of the hypothesis has been made by classical gene analysis. It was carried out in the present experiment.

\section{Material and Methods}

In order to test the validity of the three-gene hypothesis, $T$. aestivum var. Chinese Spring (haploid genotype: $n e_{1} n e_{2} \mathrm{Ne}_{3}$ ) was reciprocally crossed to T. macha var. subletshchumicum $\left(\mathrm{Ne}_{1} \mathrm{Ne}_{2} n e_{3}\right)$. The $\mathrm{F}_{1}$ hybrids were self-pollinated or backcrossed to both parents, and segregation of the necrotic plants in the $F_{2}$ and $B_{1}$ generations was studied.

To investigate the distribution of the three necrosis genes, 20 varieties of common wheat and twelve strains of synthesized hexaploids were crossed to the three test varieties, Prelude $\left(N e_{1} n e_{2} N e_{3}\right)$, Kharkov $\left(n e_{1} N e_{2} N e_{3}\right)$ and $T$. macha var. subletshchumicum $\left(\mathrm{Ne}_{1} \mathrm{Ne}_{2} n e_{3}\right)$. Their names and sources are listed in Table 1. The phenotypes of the $F_{1}$ plants produced from these crosses were observed, and the genotypes of the tested common wheat varieties and components of the synthesized hexaploids were determined.

\section{Experimental Results}

Test of the three-gene hypothesis

$\mathrm{F}_{1}$ 's between T. macha subletshchumicum and both Prelude and Kharkov, which were lethal due to severe necrosis, did not set any seeds, while those between the former and Chinese Spring were semi-lethal, bearing a limited number of seeds. For this reason, the three-gene hypothesis could be tested only with the hybrids of the latter cross combination.

In the course of monosomic analysis, Chinese Spring monosomics have been 
crossed to T. macha subletshchumicum. From these crosses necrotic or normal $\mathrm{F}_{1}$ hybrids, which were mono- or disomic, were obtained. They were self-pollinated

Table 1. List of materials

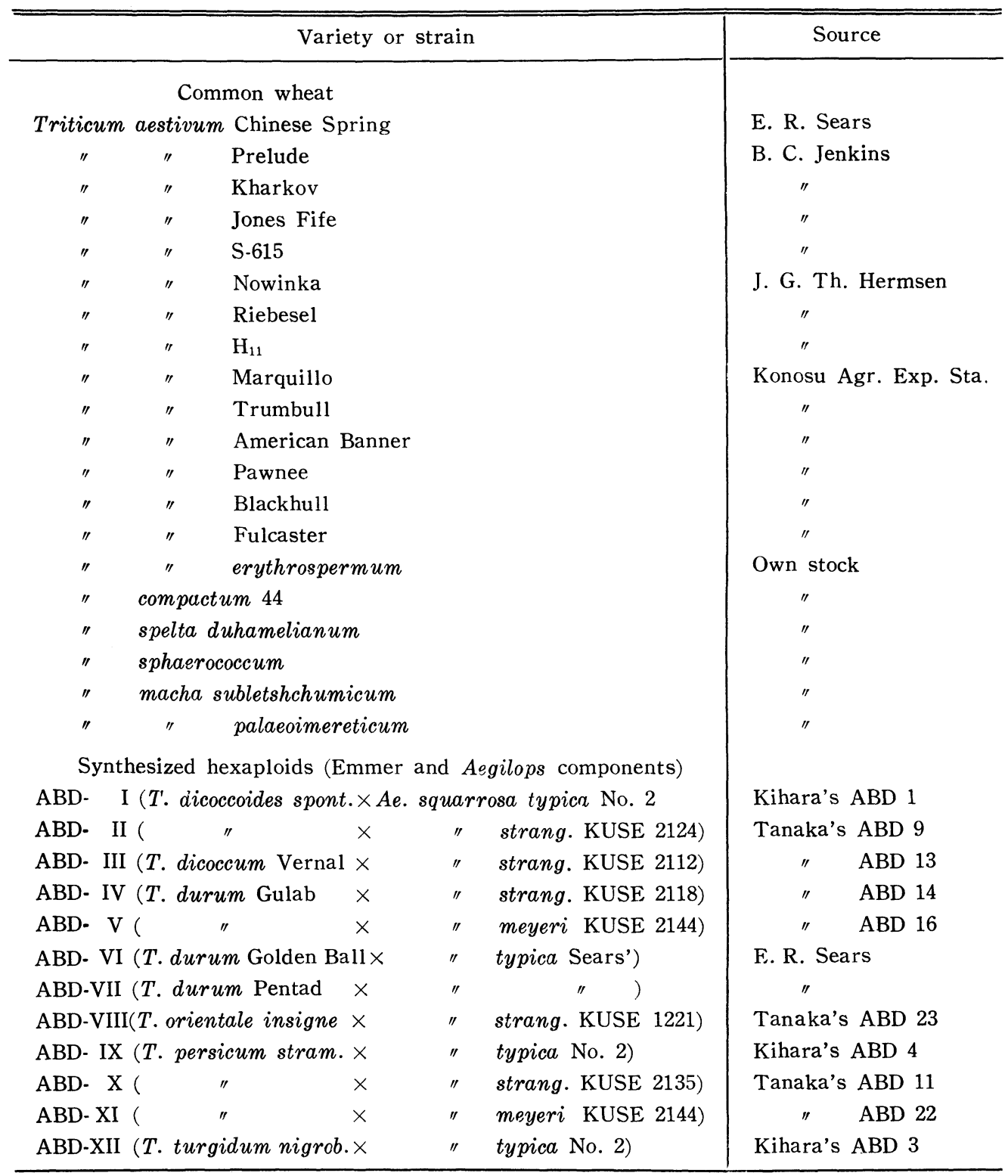

or backcrossed to both parents, and segregation of the necrotic plants in their progeny was studied. Results obtained are summarized in Table 2.

$a_{1}$ population represents the $F_{2}$ 's from the necrotic, disomic $F_{1}$ 's whose genotype is assumed according to the three-gene hypothesis to be $N e_{1} n e_{1} N e_{2} n e_{2} N e_{3} n e_{3}$. a 
Table 2. Segregation of necrotic plants in the $F_{2}$ and $B_{1}$ generations of Chinese Spring $\times T$. macha subletshchumicum

\begin{tabular}{|c|c|c|c|c|c|c|c|c|c|}
\hline \multirow{3}{*}{$\begin{array}{l}\text { Gener- } \\
\text { ations }\end{array}$} & \multirow{3}{*}{ Populations ${ }^{1)}$} & \multirow{2}{*}{\multicolumn{2}{|c|}{$\begin{array}{c}\text { No. of plants } \\
\text { observed }\end{array}$}} & \multicolumn{3}{|c|}{ Expected $^{\dagger}$} & \multicolumn{3}{|c|}{ Expected $\pi$} \\
\hline & & & & No. & f plants & & No. & of plant & \\
\hline & & Necrotic & Normal & Necrotic & Norma & $\chi^{2}$ & Necrotic & Normal & $\chi^{2}$ \\
\hline $\mathrm{F}_{2}$ & $a_{1}$ & 72 & 92 & 69.2 & 94.8 & 0.2 & 74.9 & 89.1 & 0.2 \\
\hline$" \prime$ & $a_{2}$ & 63 & 76 & 58.6 & 80.4 & 0.6 & 63.5 & 75.5 & 0.0 \\
\hline " & pooled & 135 & 168 & 127.8 & 175.2 & 0.7 & 138.4 & 164.6 & 0.2 \\
\hline $\mathrm{F}_{2}$ & $\mathrm{~b}$ & 1 & 311 & 0.0 & 312.0 & $(0.0)$ & 0.0 & 312.0 & $(0.0)$ \\
\hline $\mathrm{B}_{1}$ & c & 0 & 65 & 0.0 & 65.0 & 0.0 & 0.0 & 65.0 & 0.0 \\
\hline $\mathrm{B}_{1}$ & $d_{1}$ & 21 & 42 & 15.8 & 47.2 & 2.3 & 23.6 & 39.4 & 0.5 \\
\hline " & $\mathrm{d}_{2}$ & 17 & 12 & 7.2 & 21.7 & $17.5^{\text {***k }}$ & 10.9 & 18.1 & $5.5 *$ \\
\hline " & $\mathrm{d}_{3}$ & 41 & 58 & 24.8 & 74.2 & $14.2^{* *}$ & 37.1 & 61.9 & 0.7 \\
\hline$"$ & $\mathrm{~d}_{4}$ & 20 & 32 & 13.0 & 39.0 & $5.0^{*}$ & 19.5 & 32.5 & 0.0 \\
\hline " & pooled & 99 & 144 & 60.8 & 182.1 & $32.0 * *$ & 91.1 & 151.9 & 1.1 \\
\hline
\end{tabular}

1) See text.

+ Expected from segregation of the three major genes; $27: 37,0: 1,0: 1$ and $1: 3$ for a, $\mathrm{b}, \mathrm{c}$ and $\mathrm{d}$ populations, respectively.

It Expected from segregation of the three major genes and a modifier; 117: 139, 0:1, 0:1 and $3: 5$ for $a, b, c$ and d, respectively.

* Significant at the $5 \%$ level.

** Significant at the $1 \%$ level.

population represents the $F_{2}$ 's from the necrotic $F_{1}$ 's, which were monosomic for a non-critical chromosome and whose genotype is also supposed to be $N e_{1} n e_{1} \mathrm{Ne}_{2} n e_{2} \mathrm{Ne}_{3} n e_{3}$. If the three-gene hypothesis holds true, a 27:37 ratio for necrotic $v$ s. normal plants should be observed in these populations. The observed ratios proved to fit well the expectation as shown by $\chi^{2}$ values in the seventh column of Table 2 .

b population represents the $F_{2}$ 's from normal $F_{1}$ 's, which were monosomic for chromosome $3 \mathrm{D}$ and expected to be of the genotype, $N e_{1} n e_{1} N e_{2} n e_{2} n e_{3}$. Based on the three-gene hypothesis, all $\mathrm{F}_{2}$ plants in this population should be normal, and this actually occurred.

c population is the $B_{1}$ from backcrossing normal $F_{1}$ monosomics for chromosome $3 \mathrm{D}$ to $T$. macha subletshchumicum. This cross can be formulated as $N e_{1} n e_{1} N e_{2} n e_{2} n e_{3^{*}} \times N e_{1} N e_{1} N e_{2} N e_{2} n e_{3} n e_{3}$. Based on the three-gene hypothesis, no segregation of necrotic plants is expected in this population, and none occurred.

$d_{1}$ population is the $B_{1}$ from backcrossing disomic, necrotic $F_{1}$ 's to Chinese Spring. The genotype of the $\mathrm{F}_{1}$ plants is expected to be $N e_{1} n e_{1} N e_{2} n e_{2} N e_{3} n e_{3} \cdot \mathrm{d}_{2}$ population is the $B_{1}$ from backcrossing necrotic $F_{1}$ 's monosomic for a non-critical chromosome, having the genotype $\mathrm{Ne}_{1} n e_{1} \mathrm{Ne}_{2} n e_{2} \mathrm{Ne}_{3} n e_{3}$, to Chinese Spring. $\mathrm{d}_{3}$ population is the $B_{1}$ from backcrossing normal $F_{1}$ 's, which were monosomic for chromosome 3D, to Chinese Spring. The genotype of the $F_{1}$ 's is assumed to be $N e_{1} n e_{1} N e_{2} n e_{2} n e_{3}-\mathrm{d}_{4}$ population is the progeny of the cross, (T. compactum $44 \times$ 
T. macha subletshchumicum) $\mathrm{F}_{1} \times T$. aestivum erythrospermum. The genotype of T. macha subletshchumicum is $\mathrm{Ne}_{1} \mathrm{Ne}_{1} \mathrm{Ne}_{2} \mathrm{Ne}_{2} \mathrm{ne}_{3} n e_{3}$ and that of T. compactum 44 and T. aestivum erythrospermum was found to be $n e_{1} n e_{1} n e_{2} n e_{2} N e_{3} N e_{3}$. If the threegene hypothesis is correct, segregation of two pairs of genes must take place in all these populations, with a $1: 3$ expected ratio of necrotic vs. normal. However, actual segregation ratios deviated significantly from the expected ratio, as shown in the seventh column of Table 2 .

The simplest modification of the three-gene hypothesis for a satisfactory explanation of all the ratios so far obtained is that the homozygous condition of a recessive gene in Chinese Spring compensates for either $\mathrm{Ne}_{1}$ or $\mathrm{Ne}_{2}$. Assuming this, $117: 137,0: 1,0: 1$ and $3: 5$ ratios for the necrotic $v s$. normal plants are expected in populations $\mathrm{a}, \mathrm{b}, \mathrm{c}$ and $\mathrm{d}$, respectively. The actual ratios were compared with the expected ones and proved to fit well as shown in the last column of Table 2. The modifier assumed here might be the same as the one located on chromosome 3B (III) of Chinese Spring by Tsunewaki and Kihara (1961).

Distribution of the necrosis genes in common wheat and its ancestors

Twenty varieties of common wheat and twelve strains of synthesized hexaploids were crossed to the three test varieties. Occurrence of necrosis in their $F_{1}$ 's is summarized in Table 3.

Observation was made twice, namely, at the time of transplantation in fall and at shooting stage in spring. Necrosis appeared at different stages of development depending upon cross combination. This can be attributed to differences between the dominant alleles as shown by Hermsen (1962) or to a modifier as suggested by Tsunewaki and Kihara (1961).

The genotypes of the common wheat varieties and synthetic components of the artificially produced hexaploids were deduced from this experiment and are given in Table 4. In addition, T. dicoccum var. Khapli produced necrotic $\mathrm{F}_{1}$ hybrids when crossed to Chinese Spring. Therefore the former must have the genotype $\mathrm{Ne}_{1} \mathrm{Ne}_{1} \mathrm{Ne}_{2} \mathrm{Ne}_{2}$. The genotypes of four additional Emmer varieties are taken from Nishikawa's results (Nishikawa 1962).

The present authors' $N e_{1}$ and $N e_{2}$ genes, respectively, are the same as $L e$ (or $L e_{1}$ ) and $L e_{2}$ of Caldwell and Compton (1943), Heyne et al. (1943) and Tsunewaki (1960), and the A and B genes of Hermsen (1957) and Schmalz (1959). From their investigations it became known that ten additional varieties of common wheat have $\mathrm{Ne}_{1}$, 43 varieties have $\mathrm{Ne}_{2}$ and 44 varieties do not have either $\mathrm{Ne}_{1}$ or $\mathrm{Ne}_{2}$. All these varieties so far tested have $\mathrm{Ne}_{3}$. From this information the relative frequencies of the three necrosis genes in common wheat and its ancestors, Emmer wheat and Aegilops squarrosa, are diagrammatically shown in Fig. 1.

A majority of Emmer varieties have the genotype $N e_{1} n e_{2}$, while minor fractions are either $n e_{1} n e_{2}$ or $N e_{1} N e_{2}$. No variety is known to be $n e_{1} N e_{2}$. All Ae. squarrosa 
Table 3. Phenotypes concerning necrosis of the $F_{1}$ 's between three testers and common wheat and synthesized hexaploids

\begin{tabular}{|c|c|c|c|c|c|c|c|}
\hline \multirow{3}{*}{$\begin{array}{l}\text { Tested varieties } \\
\text { or strains }\end{array}$} & \multicolumn{6}{|c|}{ Tester (genotype) } & \multirow{3}{*}{$\begin{array}{c}\text { Haploid } \\
\text { genotype } \\
\text { of } \\
\text { tested } \\
\text { vars. }\end{array}$} \\
\hline & \multicolumn{2}{|c|}{$\begin{array}{c}\text { Prelude } \\
\left(N e_{1} n e_{2} N e_{3}\right)\end{array}$} & \multicolumn{2}{|c|}{$\begin{array}{c}\text { Kharkov } \\
\left(n e_{1} N e_{2} N e_{3}\right)\end{array}$} & \multicolumn{2}{|c|}{ T. $\underset{\left(N e_{1} N e_{2} n e_{3}\right)}{\operatorname{macha}}$ sublet. } & \\
\hline & $\begin{array}{l}\text { Early } \\
\text { observ.* }\end{array}$ & $\begin{array}{c}\text { Late } \\
\text { observ.** }\end{array}$ & Early & $\begin{array}{c}\text { Late } \\
\text { observ.**a }\end{array}$ & $\begin{array}{l}\text { Early } \\
\text { observ.* }\end{array}$ & $\begin{array}{c}\text { Late } \\
\text { observ.*** }\end{array}$ & \\
\hline Common wheat & & & & & & & \\
\hline T. aestivum Chinese Spring & - & - & - & - & - & + & $n e_{1} n e_{2} \mathrm{Ne}_{3}$ \\
\hline " Marquillo & - & - & - & - & - & + & " \\
\hline " Trumbull & - & - & - & - & - & + & " \\
\hline " American Banner & - & - & - & - & - & + & " \\
\hline$" \quad$ Pawnee & - & - & - & - & - & + & " \\
\hline " S-615 & - & - & - & - & - & + & $"$ \\
\hline " erythrospermum & - & - & - & - & - & + & " \\
\hline T. compactum 44 & - & - & - & - & - & + & " \\
\hline T. spelta duhamelianum & - & - & - & - & - & + & " \\
\hline T. macha palaeoimereticum & - & - & + & + & - & - & $N e_{1} n e_{2} n e_{3}$ \\
\hline T. aestivum Prelude & - & - & + & + & + & + & $\mathrm{Ne}_{1} n \mathrm{e}_{2} \mathrm{Ne}$ \\
\hline " Nowinka & - & - & + & + & - & + & " \\
\hline T. sphaerococcum & - & - & - & + & - & + & $"$ \\
\hline T. aestivum Kharkov & + & + & - & - & + & + & $n e_{1} N e_{2} N e_{3}$ \\
\hline " Jones Fife & + & + & - & - & + & + & " \\
\hline " Fulcaster & + & + & - & - & + & + & " \\
\hline " Blackhull & + & + & - & - & + & + & $"$ \\
\hline " $\mathrm{H}_{11}$ & + & + & - & - & + & + & $"$ \\
\hline " Riebesel & + & + & - & - & - & + & " \\
\hline $\begin{array}{c}\text { T. macha subletshchumicum } \\
\text { Synthesized hexaploids }\end{array}$ & + & + & + & + & - & - & $N e_{1} N e_{2} n e_{3}$ \\
\hline ABD-III & - & - & - & - & + & + & $n e_{1} n e_{2} \mathrm{Ne}_{3}$ \\
\hline ABD-XII & - & - & - & - & + & + & " \\
\hline $\mathrm{ABD} \cdot \mathrm{VI}$ & - & - & + & + & + & + & $\mathrm{Ne}_{1} n e_{2} \mathrm{Ne}_{3}$ \\
\hline ABD-VIII & - & - & + & + & + & + & " \\
\hline $\mathrm{ABD}-\mathrm{X}$ & - & - & + & + & + & + & $"$ \\
\hline ABD-I & - & $-(L)$ & + & + & - & $+(\mathrm{D})$ & " \\
\hline ABD-II & - & - & + & + & - & + & " \\
\hline ABD-IV & - & - & + & + & - & + & $"$ \\
\hline $\mathrm{ABD}-\mathrm{V}$ & - & - & + & + & - & + & $"$ \\
\hline ABD-VII & - & - & + & + & - & + & $"$ \\
\hline ABD-IX & - & $-(\mathrm{L})$ & + & $+(\mathrm{D})$ & - & + & $"$ \\
\hline ABD-XI & - & - & + & + & - & + & $"$ \\
\hline
\end{tabular}

+: Necrotic. - : Non-necrotic. D: Dwarf. L: Lethal at the tillering stage (Nishikawa's type II necrosis).

* Early observation made at the time of transplantation on Dec. 5, 1961.

** Late observation made at shooting stage on Apr. 26, 1962. 
Table 4. Genotypes of some varieties of common wheat and its ancestors

\begin{tabular}{|c|c|}
\hline $\begin{array}{l}\text { Haploid } \\
\text { genotypes }\end{array}$ & Varieties \\
\hline \multicolumn{2}{|l|}{ Common wheat } \\
\hline$n e_{1} n e_{2} n e_{3}$ & none \\
\hline$N e_{1} n e_{2} n e_{3}$ & T. macha palaeo. \\
\hline$n e_{1} N e_{2} n e_{3}$ & none \\
\hline$n e_{1} n e_{2} \mathrm{Ne}_{3}$ & $\begin{array}{l}\text { T. aestivum Chinese Spring, Marquillo, Trumbull, American Banner, } \\
\text { Pawnee, S- } 615 \text {, erythrospermum; T. compactum 44; T. spelta duha. }\end{array}$ \\
\hline$N e_{1} \mathrm{Ne}_{2} n e_{3}$ & T. macha sublet. \\
\hline$N e_{1} n e_{2} N e_{3}$ & T. aestivum Prelude, Nowinka; T. sphaerococcum \\
\hline$n e_{1} N e_{2} N e_{3}$ & T. aestivum Kharkov, Jones Fife, Blackhull, Fulcaster, Riebesel, $\mathrm{H}_{11}$ \\
\hline \multicolumn{2}{|l|}{ Emmer wheat } \\
\hline$n e_{1} n e_{2}-$ & T. dicoccum Vernal; T. turgidum nigrob. \\
\hline$N e_{1} n e_{2}-$ & T. dicoccoides spont.; T. persicum str.; T. orientale insigne; T. durum \\
\hline$n e_{1} \mathrm{Ne}_{2}-$ & $\begin{array}{l}\text { Gulab, Golden Ball, Pentad, reichenbachii*; T. dicoccum liguliforme* } \\
\text { none }\end{array}$ \\
\hline $\mathrm{Ne}_{1} \mathrm{Ne}_{2}-$ & T. dicoccoides kotschyanum*, straussianum*; T. dicoccum Khapli \\
\hline \multicolumn{2}{|l|}{ Aegilops squarrosa } \\
\hline$--\mathrm{Ne}_{3}$ & $\begin{array}{l}\text { typica No. 2, Sears'; strangulata KUSE 2112, KUSE 2118, KUSE } 2124 \text {, } \\
\text { KUSE 2135; meyeri KUSE } 2144\end{array}$ \\
\hline$--n e_{3}$ & none \\
\hline
\end{tabular}

* Taken from Nishikawa (1962).

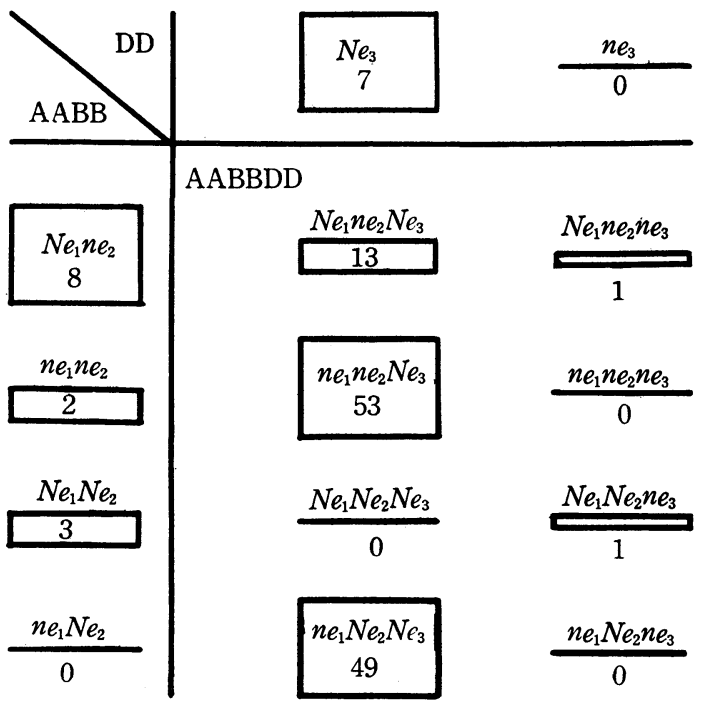

Fig. 1. Relative frequencies of different genotypes regarding necrosis in common wheat and its ancestral species.

$\square$ : Area indicates relative frequency of each genotype in the respective group. Arabian numeral indicates number of varieties having the respective genotype, 
strains so far tested have $\mathrm{Ne}_{3}$. In common wheat a great majority of varieties are either $n e_{1} n e_{2} \mathrm{Ne}_{3}$ or $n e_{1} \mathrm{Ne}_{2} \mathrm{Ne}_{3}$, each genotype representing more than 40 per cent of the examined total. The third genotype $\mathrm{Ne}_{1} n e_{2} \mathrm{Ne}_{3}$ is found in about 11 per cent of varieties. A single variety is known having each one of two other genotypes, $\mathrm{Ne}_{1} n e_{2} n e_{3}$ and $\mathrm{Ne}_{1} \mathrm{Ne}_{2} n e_{3}$. No variety was found to be either $\mathrm{Ne}_{1} \mathrm{Ne}_{2} \mathrm{Ne}_{3}$, $n e_{1} N e_{2} n e_{3}$ or $n e_{1} n e_{2} n e_{3}$.

\section{Discussion}

Monosomic analysis of complementary necrosis revealed that three necrosis genes, $\mathrm{Ne}_{1}, \mathrm{Ne}_{2}$ and $\mathrm{Ne}_{3}$ are located in chromosomes 5B (V), 2A (XIII) and 3D (XVI), respectively. This result is in accord with Hermsen's three-gene hypothesis. However, $\mathrm{B}_{1}$ and $\mathrm{F}_{2}$ data from the cross $T$. macha subletshchumicum $\times$ Chinese Spring indicated that a recessive gene in addition to the above-mentioned must be considered in the expression of necrosis.

Taking the three major genes into consideration, eight genotypes concerning necrosis can be assumed for common wheat varieties. Among them the genotype $\mathrm{Ne}_{1} \mathrm{Ne}_{2} \mathrm{Ne}_{3}$ is lacking due to necrosis. Another genotype, $n e_{1} n e_{2} n e_{3}$ will not produce any necrotic plants when crossed with all the other genotypes. Therefore, the remaining six genotypes form a necrosis hexagon, that is represented in Fig. 2.

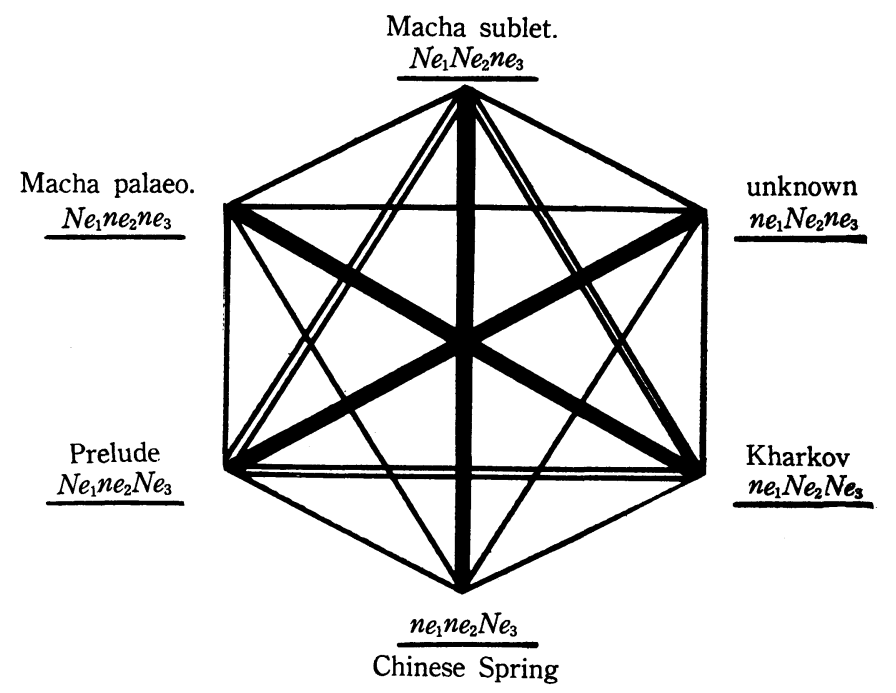

Fig. 2. Necrosis hexagon in common wheat, indicating the relatiohships among the six genotypes in regard to $F_{1}$ phenotype and $F_{2}$ segregation.

Single line: $F_{1}$ 's and $F_{2}$ 's normal. Double line: necrotic $F_{1}$ 's and segregation of 2-major genes in $F_{2}$ 's. Thick line: necrotic $F_{1}$ 's and segregation of 3-major genes in $\mathrm{F}_{2}$ 's.

Five of the seven possible genotypes are represented by at least one variety. Their representatives are also indicated in Fig. 2. No variety is known at present 
to have the remaining two genotypes, $n e_{1} n e_{2} n e_{3}$ and $n e_{1} N e_{2} n e_{3}$ but they could be selected in the progeny of the cross between $T$. macha subletshchumicum $\left(\mathrm{Ne}_{1} \mathrm{Ne}_{2} n e_{3}\right)$ and Chinese Spring $\left(n e_{1} n e_{2} \mathrm{Ne}_{3}\right)$.

As to the distribution of necrosis genes, there is a similarity in relative frequencies of $\mathrm{Ne}_{3}$ and $n e_{3}$ alleles between common wheat and Ae. squarrosa. That is, all Ae. squarrosa strain and a great majority of common wheat varieties have $\mathrm{Ne}_{3}$. This fact suggests that the Ae. squarrosa, which was the donor of $\mathrm{D}$ genome to common wheat, must have had $\mathrm{Ne}_{3}$.

T. macha is different from all other hexaploid species in possessing the $n e_{3}$ allele. It seems, therefore, to have been derived from some other hexaploid species, in which the mutation from $\mathrm{Ne}_{3}$ to $n e_{3}$ occurred. It is less likely that $T$. macha has been derived from hybridization between Emmer wheat and an $A e$. squarrosa strain that possessed $n e_{3}$, since the existence of such squarrosa strain has not been proved yet. In either case, T. macha can be considered an isolated species among the hexaploids and seems to be out of the main phylogenetic path of common wheat. This finding contradicts Kihara's previous assumption that $T$. macha might have been the progenitor of the other hexaploid species (Kihara 1959).

Two remarkable differences are noticed in the distribution of $N e_{1}$ and $N e_{2}$ at the tetra- and hexaploid levels. First the majority of Emmer varieties have the genotype $N e_{1} n e_{2}$, which is found only in a minor fraction of common wheats. Secondly, the gene combination $n e_{1} N e_{2}$ is found in a large fraction of common wheats, while it does not occur in any of the examined Emmer varieties.

Accepting the hypothesis that the donor of the $\mathrm{D}$ genome to common wheat must have had $\mathrm{Ne}_{3}$, some wild Emmer varieties of the genotype $\mathrm{Ne}_{1} \mathrm{Ne}_{2}$ can hardly be assumed to be the progenitor of common wheat, because both the $F_{1}$ 's and the amphidiploids between these Emmer varieties and Ae. squarrosa would be lethal due to necrosis. But many cultivated Emmer varieties which are either $N e_{1} n e_{2}$ or $n e_{1} n e_{2}$ can be put forward as the presumable progenitors, as proposed by Kihara and Lilienfeld (1949). The $N e_{1}, n e_{1}$ and $n e_{2}$ alleles found in the present day common wheat have to be traced back to them.

As mentioned above, no Emmer varieties so far tested have the genotype $n e_{1} N e_{2}$ and those of the genotype $N e_{1} N e_{2}$ could not have been the donors of the $\mathrm{AB}$ genomes to common wheat. These facts are in favor of the hypothesis that $\mathrm{Ne}_{2}$ of common wheat originated at the hexaploid level rather than having been derived from Emmer wheat. The prevalence of this presumably new allele in common wheat varieties suggests its selective advantage at the hexaploid level. The relative frequencies of $N e_{1} n e_{2}$ and $n e_{1} n e_{2}$ gene-combinations are reversed in Emmer and common wheats. Since other data of Tsunewaki (1962) indicated rather frequent gene exchanges between tetra- and hexaploid wheats, this shift of the gene frequency also seems to point to a special selective advantage of $n e_{1}$ or disadvantage of 
$N e_{1}$ at the hexaploid level.

\section{Summary}

1) It has been known that complementary necrosis in common wheat is mainly controlled by three genes, $N e_{1}$ located in chromosome $5 \mathrm{~B}$ (V), $N e_{2}$ in $2 \mathrm{~A}$ (XIII) and $\mathrm{Ne}_{3}$ in $3 \mathrm{D}$ (XVI). However, the $\mathrm{B}_{1}$ and $\mathrm{F}_{2}$ data from the cross T. macha subletshchumicum $\times T$. aestivum Chinese Spring indicated that a recessive gene in addition to the above-mentioned genes must be considered regarding the expression of necrosis.

2) Relationships among various varieties of common wheat concerning necrosis are represented in the diagram of Fig. 2.

3) Distribution of the three major genes in common wheat and its ancestors, Emmer wheat and Ae. squarrosa, was investigated using T. aestivum Prelude $\left(\mathrm{Ne}_{1} n e_{2} \mathrm{Ne}_{3}\right), \quad \mathrm{T}$. aestivum Kharkov $\left(n e_{1} \mathrm{Ne}_{2} \mathrm{Ne}_{3}\right)$ and T. macha subletshchumicum $\left(N e_{1} N e_{2} n e_{3}\right)$ as test varieties.

In Emmer wheat a majority of varieties were found to have the genotype $N e_{1} n e_{2}$, while minor fractions were either $n e_{1} n e_{2}$ or $N e_{1} N e_{2}$.

All strains of Ae. squarrosa so far tested had $\mathrm{Ne}_{3}$.

In common wheat, most varieties were either $n e_{1} n e_{2} N e_{3}$ or $n e_{1} N e_{2} N e_{3}$, while a small fraction were $\mathrm{Ne}_{1} n e_{2} \mathrm{Ne}_{3}$. One variety only was found to be $\mathrm{Ne}_{1} n e_{2} n e_{3}$ and another only one to be $\mathrm{Ne}_{1} \mathrm{Ne}_{2} n e_{3}$, both belonging to $T$. macha.

4) From these results, the genotypes of Emmer wheat, that supplied the $A B$ genomes to common wheat, are assumed to be $N e_{1} n e_{2}$ or $n e_{1} n e_{2}$. T. dicoccoides spontaneo-nigrum, some forms of $T$. dicoccum, $T$. turgidum, $T$. persicum and $T$. orientale, and many varieties of $T$. durum have these genotypes.

The donor of the $\mathrm{D}$ genome to common wheat must have possessed $\mathrm{Ne}_{3}$. All strains of Ae. squarrosa so far tested had this allele.

5) The presumable hexaploid progenitor must have had either $\mathrm{Ne}_{1} n e_{2} \mathrm{Ne}_{3}$ or $n e_{1} n e_{2} \mathrm{Ne}_{3}$. In common wheat, some forms of T. spelta, T. sphaerococcum, $T$. compactum and T. aestivum have these genotypes. $T$. macha, that is an exception in possessing the $n e_{3}$ allele, is considered to be an isolated species among the hexaploids and seems not to have contributed to the origin of common wheat.

6) It is suggested that $\mathrm{Ne}_{2}$ in common wheat originated at the hexaploid level rather than to have been derived from Emmer wheat. Possibility of selective advantage of $\mathrm{Ne}_{2}$ and disadvantage of $\mathrm{Ne}_{1}$ at the hexaploid level is suggested.

\section{Acknowledgements}

The authors wish to express their sincere gratitude to Dr. F. A. Lilienfeld for her critical reading of the manuscript and instructive suggestions. The authors are also greatly indebted to Mr. T. Gotô, Dr. J. G. Th. Hermsen, Dr. B. C. Jenkins, 
Dr. E. R. Sears and Dr. M. Tanaka for permitting the use of their valuable materials.

\section{Literature Cited}

Caldwell, R. M. and L. E. Compton 1943 Complementary genes in wheat causing a progressive lethal necrosis of seedlings. Jour. Hered. 34: 66-70.

Hermsen, J. G. Th. 1957 Semi-lethality in hybrid offspring of wheat. Euphytica 6: 18-25.

1959 Classification of wheat varieties on the basis of their genotype of necrosis. Ibid.

8: $37-46$.

1960 Quantitative investigations on progressive necrosis in wheat hybrids. Ibid.9:

141-172.

1961 The symbolization of complementary necrosis genes in wheat: a proposal.

W. I. S. 12: 22-23.

1962 Hybrid necrosis in wheat. (Netherlandish) Versal. landbouwk. onderz. NR. 68,5 pp. 129.

Heyne, E. G., G. A. Wiebe and R. H. Painter 1943 Complementary genes in wheat causing death of $F_{1}$ plants. Jour. Hered. 34: 243-245.

Kihara, H. 1924 Cytologische und genetische Studien bei wichtigen Getreidearten mit besonderer Rücksicht auf das Verhalten der Chromosomen und die Sterilität in den Bastarden. Mem. Coll. Sci., Kyoto Imp. Univ., Ser. B 1: 1-200.

1944 Discovery of the DD-analyser, one of the ancestors of Triticum vulgare. (Japanese) Agr. and Hort. 19 (10): 13-14.

1959 Japanese expedition to the Hindukush. Proc. 1st Int. Wheat Genetics Symp.: 243-248.

- and F. A. Lilienfeld 1949 A new synthesized 6x-wheat. Proc. 8th Int. Congr. Genet.: 307-319.

McFadden, E. S. and E. R. Sears 1944 The artificial synthesis of Triticum spelta. Genetics 30: 14 .

Nachtsheim, H. 1959 Problems of comparative genetics in mammals. Proc. 10th Int. Congr. Genet. 1: 187-198.

Nishikawa, K. 1953 A non-viable $\mathrm{F}_{1}$ hybrid between Triticum dicoccum Schübl. var. liguliforme and Aegilops squarrosa L. (Preliminary report) (Jap. with Eng. résumé) Seiken Zihô 6: 87-90.

1962 Hybrid lethality in crosses between Emmer wheats and Aegilops squarrosa, II. Synthesized $6 \mathrm{x}$ wheats employed as test varieties. Jap. Jour. Genet. 37: 227-236.

Riley, R., J. Unrau and V. Chapman 1958 Evidence on the origin of the B genome of wheat. Jour. Hered. 49: 90-98.

Roy, R. P. 1955 Semi-lethal hybrids in crosses of species and synthetic amphidiploids of Tritic$u m$ and Aegilops. Ind. Jour. Genet. P1. Breed. 15: 88-98.

Sachs, L. 1954 Reproductive isolation in Triticum. Proc. 9th Int. Congr. Genet. 2: 1145-1146.

Sarkar, P. and G. L. Stebbins 1956 Morphological evidence concerning the origin of the B genome in wheat. Amer. Jour. Bot. 43: 297-304.

Schmalz, H. 1959 Subvitale $F_{1}$-Kombinationen beim Weizen, I. Genetische Untersuchungen. Züchter 29: 207-217.

Tsunewaki, K. 1960 Monosomic and conventional gene analyses in common wheat, III. Lethality. Jap. Jour. Genet. 35: 71-75.

1962 Monosomic analysis of synthesized hexaploid wheats. Ibid. 37: 155-168.

and H. Kihara $1961 \quad \mathrm{~F}_{1}$ monosomic analysis of Triticum macha. W. I. S. 12: 1-3. 